\title{
ENSINO HÍBRIDO, TECNOLOGIAS E A NOVA ECOLOGIA COGNITIVA: UMA REVISÃO DE LITERATURA
}

\author{
BLENDED LEARNING, TECHNOLOGIES AND THE \\ NEW COGNITIVE ECOLOGY: A LITERATURE REVIEW
}

\section{EDUCACIÓN HÍBRIDA, TECNOLOGÍAS Y LA NUEVA ECOLOGÍA COGNITIVA: UNA REVISIÓN DE LA LITERATURA}

\author{
Alan César Belo Angeluci ${ }^{I}$ \\ Marcello Cacavallo ${ }^{I I}$
}

\begin{abstract}
Resumo O presente artigo revisita conceitos e autores que versam a respeito das transformações contemporâneas promovidas pelas TICs e as novas perspectivas de convergência de mídias na educação. Observando os processos comunicacionais contemporâneos por meio de autores da cibercultura, busca-se indicar conceitos que apontem para as novas tendências de ensino que estão surgindo, entre elas o ensino híbrido. Novas tecnologias comunicacionais associadas às práticas educacionais inovadoras têm permitido o desenvolvimento de plataformas digitais amplamente usadas por instituições de ensinos para cursos nos mais variados níveis educacionais. Elas permitem a interação entre professor, aluno e conteúdo mediada por ferramentas e processos que têm transformado as práticas tradicionais de ensino e aprendizagem. Para além disso, as inovações advindas desse novo cenário contemporâneo têm desenvolvido e aprimorado múltiplas inteligências, resultado de uma nova ecologia cognitiva que plasma as inteligências humanas e artificiais. Isso exige um sistema educacional que esteja comprometido com o ambiente de aprendizagem do século XXI - caracterizado pela multiplicidade de lugares (sejam eles virtuais e físicos), ideias, pessoas e perfis profissionais mais interdisciplinares, plurais e adaptados às tecnologias.

Palavras-chave: Comunicação; Cibercultura; Tecnologia; EducaÇão; Ensino Híbrido.
\end{abstract}

Universidade Municipal de São Caetano do Sul (USCS), São Caetano do Sul/SP - Brasil.

Universidade Municipal de São Caetano do Sul (USCS), São Caetano do Sul/SP - Brasil. 
Abstract This article revisits concepts and authors that deal with contemporary transformations promoted by ICT and new media convergence prospects in education. Observing the contemporary communication processes by authors of cyberculture, seeks to indicate concepts that point to new trends in education that are emerging, including the hybrid school. New communication technologies associated with innovative educational practices have allowed the development of digital platforms widely used by teaching institutions for courses in various educational levels. They allow interaction between teacher, student and content mediated tools and processes that have transformed the traditional teaching and learning practices. In addition, the innovations arising from this new contemporary scenario have developed and improved multiple intelligences, resulting into a new cognitive ecology that shapes the human and artificial intelligences. This requires an educational system that is committed to the learning environment of the 21 st century - characterized by multiplicity of places (be they virtual and physical), ideas, people and professional profiles that are more interdisciplinary, plural, and adapted to technologies.

Key-words: Communication; Cyberculture; Technology; Education; Blended Learning.

Resumen Este artículo revisa los conceptos y autores que se ocupan de las transformaciones contemporáneas promovidos por las TIC y las nuevas perspectivas de convergencia de medios en la educación. La observación de los procesos de comunicación contemporáneas de autores de la cibercultura pretende indicar conceptos que apuntan a las nuevas tendencias de la educación que están surgiendo, incluyendo la escuela híbrido. Las nuevas tecnologías de comunicación asociados con las prácticas educativas innovadoras han permitido el desarrollo de plataformas digitales ampliamente utilizados por las instituciones de enseñanza para los cursos de distintos niveles educativos. Permiten la interacción entre profesor, alumno y contenido mediada por herramientas y procesos que han transformado las prácticas de enseñanza y aprendizaje tradicionales. Las innovaciones resultantes de este nuevo entorno contemporáneo se ha centrado en el desarrollo y mejora de las inteligencias múltiples, lo que resulta en una nueva ecología cognitiva que el plasma humano y la inteligencia artificial. Esto requiere un sistema educativo que está comprometida con el ambiente de aprendizaje del siglo XXI - caracterizado por la multiplicidad de lugares (ya sea virtual y física), las ideas, las personas y los perfiles profesionales más interdisciplinares, plurales y adaptados a las tecnologías.

Palabras clave: Comunicación; Cibercultura; Tecnología; Educación; Educación híbrida.

\section{INTRODUÇÃo}

O uso de tecnologias tornou-se prática recorrente e necessária em atividades educacionais. Os cursos de Educação a Distância (EAD), por exemplo, têm evoluído a reboque da emergência de novas tecnologias. A história revela que, em seu passado, a EAD busca o suporte de plataformas de comunicação para apoiar o processo de ensino-aprendizagem. No final do século passado, até meados da primeira década do século XXI, o processo era 
suportado por mídias analógicas, fato proporcionado pela proliferação de aparelhos de videocassete (VCR). Com a evolução das mídias para a tecnologia digital, surgiu a tecnologia dos Discos Digitais Versáteis (DVD).

A evolução da informática permitiu a criação e distribuição de cursos em CD-ROM e o uso de computadores para apoio ao ensino. Posteriormente, com o surgimento da internet, as práticas EAD convergiram para o ciberespaço, sendo uma de suas principais características o compartilhamento de dados. Os cursos migraram para formatos inovadores, reconhecidos a partir do conceito de e-learning.

Este texto procura dissertar sobre a evolução EAD e a convergência dos meios de comunicação que transformaram práticas de ensino e têm sido introduzidas dentro das salas de aulas tradicionais, com o uso de diversos tipos de mídias diferentes como suporte para uso educacional.

Professores, que antes exibiam vídeos em aparelhos de VCR ou DVD acoplados a um televisor para complementar e enriquecer as explanações sobre o conteúdo programático, passaram a contar com conteúdos multimídia. As novas Tecnologias da Informação e Comunicação (TIC) permitiram a eles pesquisar e exibir tais conteúdos na hora que quiserem. Também é fundamental ressaltar a importância dos Ambientes Virtuais de Aprendizagem (AVA), as plataformas digitais que suportam todo o processo comunicacional e educacional e integram todos os tipos de mídias disponíveis num único ambiente.

No cenário do ciberespaço, ferramentas como os AVA permitiram uma inovação nos processos comunicacionais e educacionais entre escola, professores e alunos e nas estratégias de ensino e aprendizagem. Passou a ser possível ampliar o conhecimento educacional para fora da sala de aula, propagando-se o conteúdo das aulas para acesso a qualquer hora e de qualquer lugar. Conteúdo que pode estar disponível em qualquer tipo de mídia: áudio, vídeo, textos digitalizados etc.

As reflexões apresentadas nas páginas seguintes, portanto, nos remetem a mudanças que ocorreram e ainda ocorrem dentro e fora das salas de aula. Novas práticas de ensino surgem a cada dia, de acordo com as tecnologias que nos são apresentadas. Professores que antes eram somente receptores de conteúdos, apenas divulgando-os em mídias já prontas, passaram também a ser seus produtores e editores.

As práticas educacionais, ao mesmo tempo, também devem evoluir. Muito se discute hoje se os modelos de educação tradicionais (presenciais) já estariam superados e modelos educacionais totalmente a distância seriam insatisfatórios. Novas tendências estão surgindo, entre elas a mescla dos dois modelos: híbrido ou blended learning.

\section{NOVAS FRONTEIRAS POR MEIO DAS TICS}

Gabriel (2013) esclarece que a humanidade sempre é afetada em algum grau por novas tecnologias. A tecnologia não é neutra e ela pode beneficiar a espécie humana. A autora exemplifica: 
Uma das primeiras tecnologias dominadas pela humanidade e que alavanca a nossa evolução é o fogo. A partir de então, o homem começou a cozinhar os alimentos, e isso modifica o tipo de nutrientes absorvidos pelo cérebro, fazendo que ele ficasse mais denso e nos tornasse mais inteligentes (GABRIEL, 2013, p. 9).

Kenski (2012) explica que, desde os princípios da humanidade, temos a necessidade de expressar sentimentos, opiniões e de registrar nossas mais diversas experiências. Para viabilizar a comunicação entre si, a humanidade criou um tipo especial de tecnologia, a "tecnologia de inteligência". O processo comunicacional proveniente dessa tecnologia é uma inteligência imaterial, não focada na máquina em si, mas na linguagem. A linguagem pode ser oral e pode ser escrita e baseada na "síntese entre som, imagem e movimento, o processo de produção e o uso desses meios compreendem tecnologias específicas de informação e comunicação as TIC" (KENSKI, 2012, p. 27).

Avanços tecnológicos surgiram e, com eles, as formas de uso das TIC. Novas formas de produção e propagação de informações, interações e comunicação em tempo real e com enorme penetração social, como a televisão, o rádio, o cinema etc. (KENSKI, 2012). Com o aparecimento da informática, surgem as novas tecnologias de informação e comunicação.

Para Lemos (2015), o "boom" das novas tecnologias de comunicação inicia-se já no século XIX, com o desejo do homem de agir a distância da ubiquidade por meio de artefatos eletroeletrônicos como o telégrafo, o rádio, o telefone e o cinema (símbolos dos mass media). O autor ressalta, porém, que as chamadas TIC “[...] surgem a partir de 1975, com a fusão das telecomunicações analógicas com a informática, possibilitando a veiculação, sob um mesmo suporte - o computador -, de diversas formatações de mensagens" (LEMOS, 2015, p. 69).

Belloni (2012, p. 21) define as TIC como o "[...] resultado da fusão de três vertentes técnicas: a informática, as telecomunicações e as mídias eletrônicas". Nas palavras de Anderson (2010, p. 4, tradução livre), as novas TIC são uma pluralidade referente a muitas tecnologias de equipamentos, periféricos e funções eletrônicas que permitem capturar, interpretar, armazenar, receber e transmitir informações.

Essas tecnologias eletrônicas de informação e comunicação articulam-se com uma terceira linguagem, ancorada em códigos binários, por meio dos quais é possível informar, comunicar, interagir e aprender: a linguagem digital é definida como "[...] uma linguagem de síntese, que engloba aspectos da oralidade e da escrita em novos contextos" (KENSKI, 2012, p. 31).

A tecnologia digital rompe com as formas narrativas circulares e repetidas da
oralidade e com o encaminhamento contínuo e sequencial da escrita e se apre-
senta como um fenômeno descontínuo, fragmentado e, ao mesmo tempo, dinâ-
mico, aberto e veloz (KENSKI, 2012, p. 32).

Corrêa (2005) acrescenta que as TIC permitem processos comunicacionais digitais que ocorrem através de mídias também digitais. Mídia digital pode comportar, em princí- 
pio, todo e qualquer meio que se utilize da informática, transformando informações para a linguagem binária de "zeros" e "uns" - princípio da digitalização (PERNISA JÚNIOR; ALVES, 2010). Contudo, o termo se refere, na maioria das vezes, aos meios de comunicação que se utilizam da linguagem binária da informática. Incluem no conceito "as redes, como a Internet; os meios óticos - aqui também chamados suportes -, como CD, DVD e Blu-Ray; ou mesmo meios analógicos que se tornam digitais como o rádio, o cinema, a fotografia e a televisão" (PERNISA JÚNIOR; ALVES, 2010, p. 26).

\title{
A CONVERGÊnCia dos Meios de COMUniCaÇão
}

O advento das TIC suportadas por mídias digitais é chamado por Lemos (2015, p. 69) de "revolução digital", que culminou na convergência dos meios de comunicação. Trata-se de um conceito-chave para explicar as mídias digitais. Essa afirmação também é feita por Manovich (2001, p. 19, trad. do autor).

\begin{abstract}
É provável que assim como a imprensa do século XIV e a fotografia no século XIX tiveram um impacto revolucionário no desenvolvimento da sociedade e cultura modernas, hoje estamos no meio de uma revolução de novas mídias - a mudança de toda a cultura para formas de produção, distribuição e comunicação, mediadas por computador (MANOVICH, 2001, p. 19).
\end{abstract}

Posteriormente, a convergência dos meios de comunicação também é tratada por Jenkins (2009, p. 29) como:

[...] fluxo de conteúdos através de múltiplas plataformas de mídia, à cooperação entre múltiplos mercados midiáticos e ao comportamento migratório dos públicos dos meios de comunicação, que vão a quase qualquer parte em busca das experiências de entretenimento que desejam (JENKINS, 2009, p. 29).

O processo de convergências dos meios de comunicação trata da migração e substituição do processo comunicacional de acordo com o surgimento de novas tecnologias, contudo, não faz que o meio substituído desapareça. Jenkins (2009) explica que a convergência dos meios de comunicação representa uma mudança primeiro por meio das nossas relações com as mídias. O conteúdo de um meio pode mudar, por exemplo, como quando nos anos 1950, a televisão substituiu o rádio como meio de contar histórias, deixando-o livre para se tornar a principal vitrina do rock and roll (JENKINS, 2009). O público desse meio de comunicação migrou para um novo e inovador meio, porém o rádio não deixou de existir. Saltamos para o século XXI e o processo se repete. "Graças à proliferação de canais e à portabilidade das novas tecnologias de informática e telecomunicações, estamos entrando numa era em que haverá mídias em todos os lugares [...]" (JENKINS, 2009, p. 43).

Martino (2014b, p. 36) acrescenta que o processo de convergência “[...] não significa que um meio novo destrua ou invalide um meio antigo, mas entende que ambos se modificam mutuamente em uma intersecção da qual emergem novos significados". A convergên- 
cia dos meios de comunicação para plataformas digitais é um processo sem volta. Nesse mesmo pensamento, Gabriel (2013) explica que a convergência dos meios de comunicação ocorre principalmente nos dispositivos digitais devido à facilidade inerente das mídias digitais de se misturarem. Como destaca Jenkins (2009, p. 43), “[...] já estamos vivendo numa cultura da convergência".

Contudo, Aquino (2012) mostra que, apesar de ser fundamental, a tecnologia não é o único fator componente do conceito de convergência midiática. Há também um destaque para os níveis social e cultural, além do técnico.

Dentro do contexto apresentado, Goulart (2013) ressalta a importância das TIC ao subsidiar os processos comunicacionais, que abarcam ou englobam outros mais específicos, como os educacionais. Belloni (2012) lembra que as TIC não são mais relevantes ou mais eficazes do que as mídias tradicionais em qualquer situação de aprendizagem. Mas é preciso também não esquecer que, embora essas técnicas ainda não tenham demonstrado toda a sua eficiência pedagógica, elas estão cada vez mais presentes na vida cotidiana, sendo esta a razão principal da necessidade de sua integração à educação. A autora acrescenta que campos emergentes de pesquisas e de práticas como a andragogia, a mídia-educação, a Educação a Distância e a comunicação educacional podem vir a contribuir inestimavelmente para a transformação dos métodos de ensino e da organização do trabalho nos sistemas convencionais, bem como, para a utilização adequada das tecnologias de mediatização da educação (BELLONI, 2012). Coll e Illera (2010, p. 288) explicam que "[...] a incorporação das TIC nas salas de aula abre caminho para a inovação pedagógica e didática e para a busca de novas vias que visam melhorar o ensino e promover a aprendizagem".

\section{A Cibercultura e o Ciberespaço como lócus das transformaÇões}

Passarelli (2010, p. 67) acrescenta que “[...] a convergência das mídias é mais do que apenas uma mudança tecnológica; ela altera a relação entre tecnologias existentes, indústrias, mercados, gêneros e públicos". A autora explica que a convergência dos meios de comunicação "[...] modifica a lógica pela qual a indústria midiática opera e pela qual os consumidores processam a notícia e o entretenimento" (PASSARELLI, 2010, p. 67). Há também uma mudança cultural.

Se a cibercultura trata do conjunto de técnicas (materiais e intelectuais), de práticas, atitudes, modos de pensamento e valores que se desenvolvem com crescimento do ciberespaço (LEVY, 1999, p. 17), Martino (2014a) ressalta que:

A cibercultura refere-se ao conjunto de práticas levadas a cabo por pessoas conectadas a uma rede de computadores. O resultado é uma série considerável de ações e práticas que não aconteceriam, por conta da ausência de um aparato tecnológico adequado em outros momentos ou lugares. [...] A cibercultura é a transposição para um espaço conectado das culturas humanas em sua complexidade e diversidade (MARTINO, 2014a, p. 28). 
Rüdiger (2011, p. 297) também define a cibercultura como “[...] o conjunto de práticas e representações que surge e se desenvolve com a crescente mediação da vida cotidiana pelas tecnologias de informação e, assim, pelo pensamento cibernético e pela civilização maquinística".

Desde o advento da internet e das mídias digitais, o termo "ciber" é associado a ambientes e tecnologias. Ele parece implicar a conexão em rede, o digital e o espaço de ligação entre computadores (MARTINO, 2014b, p. 21). Levy (1999, p. 17) define o ciberespaço como:

\begin{abstract}
O novo meio de comunicação que surge da interconexão mundial dos computadores. O termo especifica não apenas a infraestrutura material da comunicação digital, mas também o universo oceânico de informações que ela abriga, assim como os seres humanos que navegam e alimentam esse universo (LEVY, 1999, p. 17).
\end{abstract}

Já para Martino (2014b, p. 29), o “[...] ciberespaço é a interconexão digital entre computadores ligados em rede. É um espaço que existe entre computadores, quando há uma conexão entre eles que permite aos usuários trocarem dados". Também acrescenta ao contexto que o ciberespaço é um "espaço de interação criado no fluxo de dados digitais em redes de computadores; virtual por não ser localizável no espaço, mas real em ações e efeitos" (MARTINO, 2014b, p. 11).

O ciberespaço, nas palavras de Rüdiger (2011, p. 297), é o “[...] espaço criado artificialmente pela convergência entre o mundo on-line gerado pelas redes telemáticas e as projeções imaginárias dos sujeitos que, direta ou indiretamente, interagem por ser intermédio".

Santos $(2009$, p. 5.661) explica que o ciberespaço não surgiu somente por conta da evolução da informática e de suas interfaces, mas de uma interconexão mundial entre computadores: a internet.

O ciberespaço é muito mais que um meio de comunicação ou mídia. Ele reúne, integra e redimensiona uma infinidade de mídias. Podemos encontrar desde mídias como jornal, revista, rádio, cinema e TV, bem como uma pluralidade de interfaces que permitem comunicações síncronas e assíncronas a exemplo de chats, listas, fóruns de discussão, blogs, dentre outros. A rede é a palavra de ordem do ciberespaço (SANTOS, 2009, p. 5.661).

\title{
NOVAS PERSPECTIVAS NA EDUCAÇ̃̃o CONTEMPORÂNEA
}

De acordo com Moran (2002), existem três tipos de educação: a presencial, em que professores e alunos se encontram num lugar físico chamado sala de aula (ensino convencional); a semipresencial, que acontece uma parte na sala de aula física e outra parte a distância, por meio de tecnologias; e a Educação a Distância ou virtual, que pode ter ou não momentos presenciais, mas acontece fundamentalmente com professores e alunos separados fisicamente no espaço e/ou no tempo, mas podendo estar juntos através das TIC.

Oliveira (2014) explica que a educação presencial ocorre no mesmo espaço físico e no mesmo momento temporal. Já na modalidade a distância, os professores podem estar 
separados geograficamente e de forma temporal, mas podem estar conectados através do uso das tecnologias. "Esta modalidade de educação é efetivada através do uso intensivo de tecnologias de informação e comunicação (TIC), podendo ou não apresentar momentos presenciais" (OLIVEIRA, 2014, p. 15).

Desde seus primórdios, a Educação a Distância (EAD) fez usos de tecnologias, representadas pelo correio postal, rádio e televisão; contudo, mais recentemente, as TIC mediadas por computador passaram a ser utilizadas no âmbito da educação como apoio às atividades docentes, sobretudo na apresentação dos conteúdos de aprendizagem (MACHADO; LONGHI; BEHAR, 2013).

Passarelli (2007, p. 49) define a EAD “[...] como aquela onde professor e aluno estão distantes geograficamente". Também acrescenta o conceito de midiatização no processo de aprendizagem, uma vez que a distância física entre eles necessita ser vencida por algum meio de comunicação, como mídia impressa, telefone, rádio, televisão, vídeos, computadores, CD-ROM, internet, videoconferência e outros (PASSARELLI, 2007, p. 49).

Já Carvalho (2014) explica que a EAD desde o seu surgimento remoto como modalidade de educação é acompanhada de perto pelo desenvolvimento das TIC, adequando-se às novas velocidades e a cada modalidade disponível para o fluxo da informação.

Moore e Kearsley (2007) reforçam esse conceito, evidenciando a EAD em cinco gerações em função das tecnologias vigentes em cada época. A primeira geração (1880) é marcada pelo início do ensino por correspondência por meio dos serviços postais. O surgimento e a difusão do rádio e da televisão, a partir da década de 1920, trouxeram o ensino através desses dois veículos de comunicação, possibilitando a propagação da informação em massa, caracterizando a segunda geração de EAD. Já a terceira geração (1960) é marcada por uma difusão de conhecimento de maneira organizada, com o uso de diferentes ferramentas tecnológicas da época, incluindo o telefone e o fax. A quarta geração de EAD veio com o lançamento dos satélites de comunicação, tornando viável o ensino através do áudio e da videoconferência. A quinta e última geração de EAD é marcada pela popularização do computador e da consolidação da internet a partir da década de 1990, rompendo definitivamente qualquer barreira física e atingindo uma nova dimensão.

\section{Do E-LEARNING AO B-LEARNING}

E-learning é o termo abreviado de eletronic-learning, e é uma modalidade de EAD mediada por computadores, que, devido à convergência dos meios de comunicação para as novas tecnologias de redes conectadas, possível graças ao advento da internet, fez esse sistema de aprendizado transformar-se em um grande propulsor de conhecimento.

$\mathrm{O}$ conceito de e-learning é amplo. Tradicionalmente, o aprendizado apoiado em computadores podia ser autogerenciado por meio de programas educacionais disponibilizados por CD-ROM ou qualquer multimídia (MOORE; KEARSLEY, 2014). Contudo, para Gomes (2005, p. 232), o conceito de e-learning “[...] engloba elementos de inovação e distinção em relação a outras modalidades de utilização das tecnologias da educação e apresenta 
um potencial acrescido em relação a essas mesmas modalidades". A pesquisadora defende que o termo e-learning está intrinsecamente associado à internet (GOMES, 2005, p. 232).

Conforme Passarelli (2010, p. 57), a partir dos anos 1990, “[...] a Internet invadiu todas as instâncias da vida pública e privada instituindo a 'virtualidade' da vida digital como outra instância do "real"'.

O pesquisador espanhol Almenara (2006, p. 2, trad. do autor) também acrescenta que a formação educacional ancorada em uma rede, mediada por computadores, se refere a uma modalidade de formação a distância que se apoia nessa rede e que facilita a comunicação entre professor e os alunos segundo determinadas ferramentas síncronas e assíncronas da comunicação.

O autor também lista todas as características desse processo, conforme o Quadro 1.

Quadro 1 - Características da formação em rede

\section{Características da formação em rede}

- Uso de aprendizagem mediado por computador

- Uso de navegadores web para acessar as informações

- Conexão professor - alunos separados por espaço e tempo

- Utilização de diferentes ferramentas de comunicação síncronas e assíncronas

- Multimídia

- Hipertextual - hipermídia

- Armazenamento, manutenção e administração do conteúdo sobre um servidor web

- Aprendizagem flexível

- Aprendizagem apoiada em tutoriais

- Materiais digitais

- Aprendizagem individualizada versus colaborativa

- Interação

Fonte: ALMENARA (2006, p. 3).

Entre todas essas características, uma das principais do e-learning é a sua potencialidade devido à facilidade de acesso à informação independentemente do momento temporal e do espaço físico (GOMES, 2005), o que significa que se trata de um processo comunicacional que pode ser síncrono ou assíncrono. No modo síncrono, alunos podem assistir às aulas, palestras educacionais, conferências científicas de qualquer parte do mundo através de ferramentas conectadas à web, como o Skype. Já no modo assíncrono, as aulas, palestras e conferências não acontecem ao mesmo tempo. 
As pesquisadoras portuguesas Martins, Justino e Gabriel (2010, p. 7) definem que "a comunicação síncrona implica que os participantes se encontrem num mesmo espaço de (físico ou on-line) e num momento específico de modo a poderem comunicar entre si ou trocar informações".

As mídias e ambientes síncronos possuem como principal característica a interatividade que é gerada pela presença de seus participantes (MIRANDA; DIAS, 2003). São exemplos de mídias síncronas as teleconferências, as audioconferências, as videoconferências, as conferências mediadas por meio de plataformas digitais formadas por redes de computadores conectadas à internet, as webconferences e os chats públicos e privados.

Por sua vez, Lemos (2015) explica que vivemos a fase da comunicação e da informação digital, permitindo escapar do tempo linear e do espaço geográfico, conceitos aplicados à comunicação assíncrona.

Reid apud Recuero (2009, p. 37) conceitua que "[...] na comunicação assíncrona, não se espera resposta imediata do ator por não estar presente no momento temporal da interação, tem-se como exemplo o e-mail’". Para Martins, Justino e Gabriel (2010, p. 3) "[...] neste tipo de comunicação a transmissão da informação ocorre de modo diferido, não exigindo, por isso mesmo, a disponibilidade ou a presença simultânea dos interlocutores". Outros exemplos de mídias digitais assíncronas são os websites, os webstreamings, os DVDs, os CD-ROMs e os webforuns.

Outra característica de e-learning que merece ser destacada é a interatividade.

De acordo com Lemos (1997), interatividade é uma palavra de ordem das mídias eletrônicas, e a interatividade está diretamente ligada às novas mídias digitais. O autor acrescenta que "[...] o que compreendemos hoje por interatividade, nada mais é que uma nova forma de interação técnica, de cunho 'eletrônico digital' diferente da interação 'analógica' que caracterizou os medias tradicionais” (LEMOS, 1997, p. 1).

Nas palavras dos pesquisadores, cientistas em cibercultura Primo e Cassol (1999, p. 65):

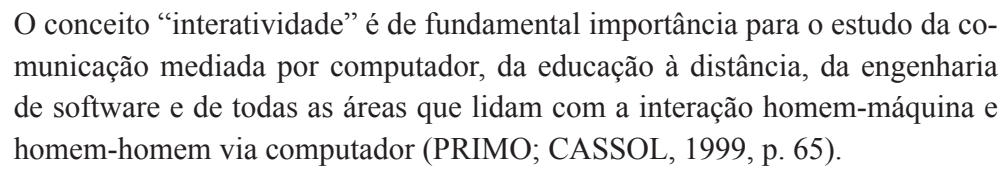

Primo e Cassol (1999) discorrem sobre o conceito de interatividade nas diversas ciências, como a física, a filosofia, a sociologia, a geografia, a biologia, a química, mas é nos estudos da informática que o termo ganha força por meio da evolução dos computadores e suas interfaces.

Outro conceito para a interatividade é apresentado por Machado apud Primo e Cassol (1999), em que o autor salienta a característica da bidirecionalidade do processo, em que o fluxo da comunicação se dá em duas direções. Define-se como processo de bidirecionalidade de comunicação aquele no qual "[...] os polos emissor e receptor são intercambiáveis e dialogam entre si durante a construção da mensagem”. 
O conceito de e-learning pode também estar associado a um híbrido de atividades presenciais e atividades não presenciais, a distância, suportado por serviços e tecnologias disponíveis na internet. Dentro desse contexto, Gomes (2005, p. 234) explica que:

\footnotetext{
Nesta perspectiva, determinadas unidades de ensino podem ser abordadas presencialmente e outras a distância, ou dentro da mesma unidade, certos componentes de uma mesma unidade e ser explorados em sala de aula (ou laboratório) e outros podem ser explorados a distância com base nos recursos da Internet (GOMES, 2005, p. 234).
}

Trata-se de um modelo misto, que incorpora componentes de formação on-line com componentes de formação presencial, chamado b-learning (blended learning) (GOMES, 2005).

Almeida (2003, p. 333) já indicava o blended learning como "[...] uma tendência potencial da EAD, apontando integrar diferentes tecnologias e metodologias de aprendizagem".

Na visão de Fava (2014), o blended learning é tratado como um termo emanado do e-learning que se refere a um sistema de ensino e aprendizagem no qual existem conteúdos ofertados a distância e conteúdos necessariamente ofertados face to face. $\mathrm{O}$ autor destaca que b-learning é um modelo educacional híbrido e flexível, em que existirá sempre uma parte mediada por tecnologia e outra com componente de presencialidade. Próximo do conceito do e-learning, o modelo é estruturado com atividades síncronas e assíncronas que dispensam a participação simultânea (FAVA, 2014, p. 36).

Segundo Moore e Kearsley (2014, p. 127), o blended learning é um tipo de aprendizado que envolve normalmente uma série de aulas ou sessões de treinamento presenciais que "[...] são complementadas com o uso da web ou de um sistema de gerenciamento do aprendizado para acesso a recursos de aprendizado, realização de testes, tarefas ou notas".

Por um lado, a "educação tradicional" sempre lançou mão de atividades não presenciais como parte de seu programa e métodos. Por outro, é cada vez mais comum a existência de encontros presenciais ao vivo em cursos que se denominam "a distância", não presenciais (TORI, 2010, p. 27). O autor acrescenta que, conforme os cursos tradicionais ampliarem a utilização de recursos virtuais e os cursos a distância absorverem mais atividades presenciais ao vivo, ficará cada vez mais difícil separar essas modalidades de ensino. O fenômeno da convergência entre virtual e presencial na educação é chamado de blended learning (TORI, 2010, p. 29).

\section{ENSINO HÍBRIDO COMO TENDÊNCIA}

No Brasil, o termo é também denominado ensino híbrido. Moran (2015) explica que blended significa misturado, mesclado, híbrido. O pesquisador lembra que a educação sempre foi misturada, híbrida, combinando tempos, espaços, atividades, metodologias e públicos. Com o advento da conectividade e, mais recentemente, da mobilidade, o híbrido na educação é muito mais perceptível, amplo e profundo (MORAN, 2015). 
Valente (2015) explica que o ensino híbrido segue uma tendência de mudança e inovação que ocorreu praticamente em todos os serviços e na produção de bens que incorporam os recursos das tecnologias digitais, como a informatização do sistema bancário, do comércio e da indústria. As transformações ocorridas fizeram que o foco das atividades, que estava nos agentes que proviam esses serviços, passasse para os usuários. Dentro desse contexto, o ensino híbrido tem que ser entendido não como um modismo que cai de paraquedas na educação, mas algo que veio para ficar (VALENTE, 2015).

Os pesquisadores em comunicação e ensino híbrido Bacich, Tanzi Neto e Trevisani (2015, p. 51-52) ressaltam que a importância do uso das tecnologias digitais na escola, possibilitando a personalização do ensino, é um desafio para muitos educadores. Os autores dão uma definição mais completa para o "ensino híbrido": a expressão está enraizada em uma ideia de educação híbrida que ocorre de diferentes formas e em diferentes espaços, sendo que não existe uma maneira única de aprender, e na qual a aprendizagem é um processo contínuo.

De uma maneira geral, o ensino híbrido trata da convergência dos modelos educacionais: o presencial, em que o processo ocorre em sala de aula, como acontece há tempos, e o modelo on-line, que utiliza as tecnologias digitais para promover o ensino. Considera-se que esses dois ambientes de aprendizagem, a sala de aula tradicional e o espaço virtual, tornam-se gradativamente complementares (BACICH; TANZI NETO; TREVISANI, 2015, p. 52). Os autores explicam que "[...] isso ocorre porque, além do uso de variadas tecnologias digitais, o indivíduo interage com o grupo, intensificando a troca de experiências que ocorre em um ambiente físico, a escola".

\section{Ambientes Virtuais de Aprendizagem (AVA)}

Dentro das principais tecnologias digitais e de suporte à educação on-line estão, sem dúvida, os ambientes virtuais de aprendizagem (AVA). Trata-se de ferramenta potencial na divulgação da informação, da comunicação e da aprendizagem, seja ela, presencial, a distância ou híbrida.

Os AVA são conhecidos como plataformas de EAD por empregarem, principalmente, uma infraestrutura tecnológica com suficientes recursos para atender aos objetivos pedagógicos dessa modalidade de ensino. São chamados de LMS (Learning Managements System) ou softwares desenvolvidos com base em um (ou mais de um) pressuposto pedagógico (MACHADO; LONGHI; BEHAR, 2013).

Nas palavras de Santos (2009, p. 5.664), os AVA possuem uma das principais características da internet: a convergência das mídias e a capacidade de hibridizar e permutar num mesmo ambiente várias mídias. A autora acrescenta que os AVA são como "[...] uma organização viva, em que seres humanos e objetos técnicos integram num processo complexo que se auto-organiza da dialógica de suas redes de conexões".

Machado, Longhi e Behar (2013, p. 58) definem os AVA como "espaços na Internet relacionados à organização a cursos e disciplinas, à administração de conteúdos e ao monito- 
ramento de alunos nas modalidades presencial, e-learning e blended learning". Os autores explicam que os AVA conduzem transformações no ensino e na aprendizagem.

Pereira, Schmitt e Dias (2007, p. 4) conceituam os AVA em mídias compostas de ferramentas e recursos tecnológicos resultantes da evolução das TIC, os quais permitem a emissão e a recepção de mensagens e utilizam o ciberespaço para veicular conteúdos e permitir interação entre os atores do processo educativo. As autoras alertam que o desenvolvimento de ferramentas ancoradas na web incentiva cada vez mais a utilização dos AVA como apoio ao ensino, seja ele e-learning ou híbrido.

As pesquisadoras também descrevem os principais recursos apoiados nas TIC que geralmente suportam o funcionamento dos AVA, divididos em quatro eixos (PEREIRA; SCHMITT; DIAS, 2007):

1. Informação e documentação: permite apresentar as informações institucionais do curso, veicular conteúdos e materiais didáticos, fazer upload de arquivos e oferecer suporte ao uso do ambiente;

2. Comunicação: facilita a comunicação síncrona e assíncrona;

3. Gerenciamento pedagógico e administrativo: permite acessar as avaliações e o desempenho dos aprendizes, consultar a secretaria virtual do curso, entre outros;

4. Produção: permite o desenvolvimento de atividades e resoluções de problemas dentro do ambiente.

No entanto, as TIC integradas aos AVA suportam um universo virtual que não é composto somente da tecnologia e do gerenciamento das informações, mas também dos atores participantes e suas interações. Morais e Cabrita (2008) lembram que, independentemente das ferramentas de comunicação utilizadas, o que importa é que elas, incluindo os AVA, consigam desenvolver e melhorar a interatividade entre os diversos atores, principalmente entre professores e alunos.

\section{O PROFESSOR NO CENTRO DA DISCUSSÃO}

Pessoni e Akerman (2014, p. 28) tratam dessa transformação e afirmam que, com a “[...] chegada da Geração Y (indivíduos nascidos após 1978 às salas de aulas, cada vez mais os professores são forçados a repensar o modelo de ensino, tornando as aulas mais dinâmicas e agregando tecnologia ao saber".

Esses estudantes, chamados de "nativos digitais", pensam e processam a informação de modo diferente dos seus antecessores e se contrapõem às gerações anteriores, "os imigrantes digitais" (PRENSKY apud CAPRINO; PESSONI; APARÍCIO, 2103, p. 14).

O conceito também é pesquisado por Passarelli, Junqueira e Angeluci (2014, p. 162), segundo os quais esses jovens "[...] imersos na cultura das novas mídias as consideram como parte integral de seu cotidiano e as utilizam de maneira diferencial se comparada às gerações anteriores".

Dentro do modelo educacional, muitos dos professores em atividade são nascidos e formados nessas gerações anteriores: "Imigrantes digitais seriam então aqueles que estão 
em processo de aprendizagem e adaptação de aspectos e características que são genuínas e naturais aos nativos digitais" (PASSARELLI; JUNQUEIRA; ANGELUCI, 2014, p. 162).

É inegável que as inovações causadas pelo avanço das TIC na área da educação, principalmente aquelas que incorporaram a internet como suporte para a Educação a Distância (EAD), geraram uma mudança nos perfis dos seus atores, configurando novas formas de ensinar e aprender. "Ao mesmo tempo, verifica-se que o perfil dos alunos está em transformação, exigindo a revisão das práticas pedagógicas e dos professores" (SCHENEIDER; SILVA; BEHAR, 2013).

Passarelli afirma que "[...] o mundo globalizado, caracterizado por intensos fluxos de capitais, produtos e informação passa a exigir de seus cidadãos novas competências" (PASSARELLI, 2007, p. 40).

Esses conceitos nos trazem a outras mudanças. Se as práticas pedagógicas sofreram alteração, também surge a necessidade de modificar os docentes. Novos papéis são criados a partir das novas tecnologias digitais na Educação a Distância, surgindo a figura do tutor. A função do tutor é vista de forma diferente da do professor. Enquanto o último elabora, organiza o conteúdo e prepara o material a ser utilizado nos cursos, o primeiro desempenha um papel de mediador entre o material didático e o aluno (ESPÍNDOLA; NASCIMENTO, 2014). Tal conceito é reforçado por Fava (2014, p. 37), para quem "[...] o professor presencial é o responsável pelos conteúdos e o professor a distância, o responsável por fazer a tutoria, orientação e atendimento dos discentes".

Esse contexto também é aplicado ao ensino híbrido. Valente $(2015$, p. 7) alerta que “[...] a implantação do ensino híbrido requer a boa formação do professor, a adequação do currículo, bem como das atividades curriculares e da dinâmica de sala de aula".

De acordo com Bacich, Tanzi Neto e Trevisani (2015), a interação e o envolvimento com tecnologias digitais alteraram o papel desempenhado pelos professores e por seus alunos.

Novas competências e habilidades são necessárias ao professor da EAD em tempos de tecnologias digitais, sejam elas híbridas ou não. Aprender a lidar com elas torna-se obrigatório. Bliska (2010, p. 189) explica que “[...] as tecnologias permitem a realização de um maior número de atividades com menos esforço, mas, destituídas de educação, conhecimentos e aplicações adequados, são infrutíferas" (BLISKA, 2010, p. 189). Nas palavras de Passarelli (2007, p. 85):

\footnotetext{
Você não precisa só adquirir as habilidades de encontrar coisas, precisa também adquirir as habilidades de usar estas coisas em sua vida [...] os recursos da Internet são fundamentais tanto para o ensino-aprendizagem quanto para o auto-aprimoramento das competências pessoais (PASSARELLI, 2007, p. 85).
}

\section{CONSIDERAÇõES FINAIS}

Vivemos num início de século XXI em que a cultura digital está incorporada ao dia a dia de todos nós. Aparelhos que comunicam, aparelhos que agora são smart, inteligentes, que mudam a todo instante as nossas vidas. 
Essa cultura digital está unificada nos mais diversos segmentos da sociedade, e não seria diferente no contexto educacional. Este artigo mostra que a educação e a tecnologia sempre caminharam e caminham juntas, seja em cursos tradicionais, seja em cursos a distância, ou em modelos de ensino híbrido. Com a convergência dos meios de comunicação para o ciberespaço, a integração das tecnologias de comunicação digitais às práticas escolares fortalece ainda mais o modelo híbrido.

Contudo, o sucesso do modelo de ensino híbrido só ocorre devido aos processos comunicacionais contemporâneos. Isso ocorre desde a forma híbrida de postar conteúdo educacional por meio das diversas plataformas digitais disponíveis, inclusive os chamados Ambientes Virtuais de Aprendizagem (AVA), fazendo uso de vários tipos de mídias, até o processo de convergência dos meios de comunicação para dentro do ciberespaço, o que permite aos alunos estudarem com uma maior flexibilização de espaço e de tempo.

\section{REFERÊNCIAS}

ALMEIDA, M. E. B. Educação a distância na internet: abordagens e contribuições dos ambientes digitais de aprendizagem. Educação e Pesquisa. São Paulo, v. 29, n. 2a, p. $327-$ 340, jul./dez. 2003.

ALMENARA, J. C. Bases pedagógicas del e-learning. Revista de Universidad y Sociedad del Coocimiento. Barcelona, ES, v. 3, n. 1, p. 1-10, abril 2006.

ANDERSON, J. ICT transforming education: a regional guide, 1. ed. Bangkok, Tailândia: UNESCO, 2010.

AQUINO, M. C. Convergência entre televisão e web: proposta de categorização analítica. Tese (Doutorado em Comunicação). Porto Alegre: PPGCOM, UFRGS, 2012.

BACICH, L.; TANZI NETO, A.; TREVISANI, F. D. M. Ensino híbrido: personalização e tecnologia na educação. In: BACICH, L.; TANZI NETO, A.; TREVISANI, F. D. M. Ensino híbrido: personalização e tecnologia na educação, 1. ed. Porto Alegre: Penso, 2015. Cap. 2, p. 47-65.

BELLONI, M. L. O que é mídia-educação, 3. ed. Campinas: Autores Associados, 2012.

BLISKA, A. Capital social em comunidades virtuais de aprendizagem e de prática. In: PASSARELLI, B.; AZEVEDO, J. Atores em rede: olhares luso-brasileiros, 1. ed. São Paulo: SENAC, 2010, p. 187-220.

CAPRINO, M. P.; PESSONI, A.; APARICIO, A. S. M. Mídia e educação - a necessidade do multiletramento. Comunicação e inovação. São Caetano do Sul, v. 14, n. 26, p. 13-19, jan./jun. 2013.

CARVALHO, C. A. M. D. Avaliando as ferramentas na EAD: diferentes possibilidades frente a um mundo de novas TICs. In: COELHO, F. J. F.; VELLOSO, A. Educação a distância: história, personagens e contextos, 1. ed. Curitiba: CRV, 2014. Cap. 3, p. 43-49. 
COLL, C.; ILLERA, J. L. R. Alfabetização, novas alfabetizações e alfabetização digital: as TIC no currículo escolar. In: COLL, C.; MONEREO, C. Psicologia da Educação Virtual: aprender e ensinar com as tecnologias da informação e da comunicação. Porto Alegre: Artmed, 2010, p. 289-310.

CORRÊA, E. S. Comunicação digital: uma questão de estratégia e de relacionamentos com públicos. Organicom-Revista Brasileira de Comunicação Organizacional e Relações Públicas. São Paulo, v. 2, n. 3, p. 94-111, $2^{\circ}$. semestre 2005.

ESPÍNDOLA, C. D. S. O.; NASCIMENTO, R. S. O professor, a disciplina e os conteúdos na EAD. In: COELHO, F. J. F.; VELLOSO, A. Educação a distância - história personagens e contexto, 1. ed. Curitiba: CRV, 2014, p. 51-67.

FAVA, R. Educação 3.0, 1. ed. São Paulo: Saraiva, 2014.

GABRIEL, M. Educar: a (r)evolução digital na educação, 1. ed. São Paulo: Saraiva, 2013.

GOMES, M. J. E-learning: reflexões em torno do conceito. Challenges 05 - Congresso Internacional sobre Tecnologias da Informação e Comunicação na Educação. Braga, Portugal: Universidade do Minho, 2005, p. 229-236.

GOULART, E. E. Aluno 3.0: antigo personagem em nova comunicação. In: PESSONI, A.; PERAZZO, P. F. Neorreceptor: no fluxo da comunicação, 1. ed. Porto Alegre: EDIPUCRS, 2013, p. 67-87.

JENKINS, H. Cultura da convergência, 2. ed. São Paulo: Aleph, 2009.

KENSKI, V. M. Educação e tecnologias: O novo ritmo da informação, 8. ed. Campinas: Papirus, 2012.

LEMOS, A. Anjos interativos e retribaliação do mundo. Sobre interatividade e interfaces digitais. UFBA. Salvador, p. 5, 1997.

Cibercultura: tecnologia e vida social na cultura contemporânea, 7. ed. Porto Alegre: Sulina, 2015.

LEVY, P. Cibercultura, 1. ed. São Paulo: Editora 34 Ltda., 1999.

MACHADO, L. R.; LONGHI, M. T.; BEHAR, P. A. Domínio tecnológico. In: BEHAR, P. A. Competências em educação a distância. Porto Alegre: Penso, 2013, p. 56-80.

MANOVICH, L. The language of new media, 1. ed. Cambridge: Massachusetts Institute of Technology, 2001.

MARTINO, L. M. S. Teoria da Comunicação, 5. ed. Petrópolis, RJ: Vozes, 2014a.

. Teoria das mídias digitais: linguagens, ambientes e redes. Petrópolis, RJ: Vozes, 2014b.

MARTINS, A. B. J.; JUSTINO, A. C. F. C.; GABRIEL, G. D. C. F. SBIDM: comunicação síncrona, assíncrona e multidireccional. Políticas de Informação na Sociedade em Rede. 
Guimarães, v. 10, n. ACTAS - congresso nacional de bibliotecários, arquivistas e documentalistas, abril 2010.

MIRANDA, L.; DIAS, P. Ambientes de comunicação síncrona na web como recurso de apoio à aprendizagem de alunos do ensino superior. Conferência Internacional de Tecnologias de Informação e Comunicação na Educação, Simpósio Internacional de Informática Educativa. Braga, Portugal, n. III Challengers 2003, p. 239-250, 2003.

MOORE, M. G.; KEARSLEY, G. Educação a distância: uma visão integrada, 1. ed. São Paulo: Thomson Learning, 2007.

. Educação a distância - sistemas de aprendizado on-line, 3. ed. São Paulo: Cengage, 2014.

MORAIS, N. S.; CABRITA, I. Ambientes virtuais de aprendizagem: comunicação (as) síncrona e interação no ensino superior. Prisma.com. Porto, v. 6, n. 1a, p. 158-178, 2008.

MORAN, J. M. O que é educação a distância? Universidade de São Paulo. São Paulo, 2002. (Disponível em http://www2.eca.usp.br/moran/wp-content/uploads/2013/12/dist. pdf. Acesso em: 12 out. 2015.)

. Educação híbrida. In: BACICH, L.; TANZI NETO, A.; TREVISANI, F. D. M. Ensino híbrido: personalização e tecnologia na educação, 1. ed. Porto Alegre: Penso, 2015, p. 27-45.

OLIVEIRA, M. S. A história da educação a distância e contexto atual. In: COELHO, F. J. F.; VELLOSO, A. Educação a distância: história, personagens e contextos, 1. ed. Curitiba: CRV, 2014, p. 15-35.

PASSARELLI, B. Interfaces digitais na educação: @lucin[ações] consetidas, 1. ed. São Paulo: SENAC, 2007.

. Literacias emergentes nas redes sociais: estado da arte e da pesquisa qualitativa no observatório da cultura digital. In: PASSARELLI, B.; AZEVEDO, J. Atores em rede: olhares luso-brasileiros, 1. ed. São Paulo: SENAC, 2010, p. 63-78.

PASSARELLI, B.; JUNQUEIRA, A. H.; ANGELUCI, A. C. B. Os nativos digitais no Brasil e seus comportamentos diante das telas. Matrizes. São Paulo, v. 8, n. 1, p. 159178, jan./jun. 2014.

PEREIRA, A. T. C.; SCHMITT, V.; DIAS, M. R. Á. C. Ambientes virtuais de aprendizagem. In: PEREIRA, A. T. AVA - ambientes virtuais de aprendizagem em diferentes contextos, 1. ed. Rio de Janeiro: Ciência Moderna, 2007, p. 2-22.

PERNISA JUNIOR, C.; ALVES, W. Comunicação digital: jornalismo, narrativas, estética. Rio de Janeiro: MauadX, v. 1a., 2010.

PESSONI, A.; AKERMAN, M. O uso de mídias sociais em saúde: a adoção por docentes e discentes do ensino superior. In: GOULART, E. E. Mídias sociais: uma contribuição de análise, 1. ed. Porto Alegre: EDIPUCRS, 2014, p. 27-54. 
PRIMO, A. F. T.; CASSOL, M. B. F. Explorando o conceito de interatividade: definições e taxanomias. Informática na educação: teoria \& prática. Porto Alegre, v. 2, n. 2a., p. 65-80, outubro 1999.

RECUERO, R. Redes sociais na internet, 1. ed. Porto Alegre: Sulina, 2009.

RUDIGER, F. As teorias da cibercultura - perspectivas, questões e autores, 2. ed. Porto Alegre: Sulina, 2011.

SANTOS, L. C. N. Ensino Híbrido: Universidade Metodista de São Paulo [18 nov. 2015]. São Bernardo do Campo. A entrevista transcrita na íntegra consta no Apêndice B dessa dissertação.

SCHENEIDER, D.; SILVA, K. K. A.; BEHAR, P. A. Competência dos atores da educação a distância. In: BEHAR, P. A. Competência em educação a distância, 1. ed. Porto Alegre: Penso, 2013, p. 152-173.

TORI, R. Educação sem distância, 1. ed. São Paulo: SENAC, 2010.

VALENTE, J. A. O ensino híbrido veio para ficar. In: BACICH, L.; TANZI NETO, A.; TREVISANI, F. D. M. Ensino Híbrido: personalização e tecnologia na educação, 1. ed. Porto Alegre: Penso, 2015, p. 13-17.

\section{Dados dos Autores}

\section{Alan César Belo Angeluci}

Doutor em Ciências pela Universidade de São Paulo. Professor do Programa de Pós-graduação em Comunicação e em Educação da Universidade Municipal de São Caetano do Sul. São Caetano do Sul/SP - Brasil. aangeluci@uscs.edu.br

\section{Marcello Cacavallo}

Mestre em Comunicação pela Universidade Municipal de São Caetano do Sul. Professor nos cursos de Ciências Contábeis, Gestão Financeira, Administração de Empresas e Comunicação Institucional da Faculdade Sumaré. São Paulo/SP - Brasil. mcacavallo@gmail.com

Submetido em: 04-04-2016

Aceito em: 02-05-2017 